\title{
Analysis and Optimize of the Vibration of Mini-Electrical Vehicle Frame
}

\author{
Ruo-xun FAN ${ }^{1, a}$,Jie Liu ${ }^{1}$,Tan-li Wang ${ }^{1}$ and Hong-fei Xue ${ }^{2}$ \\ ${ }^{1}$ Liaoning University of Technology, Jinzhou 121001,China; \\ ${ }^{2}$ Great Wall Motor Company Limited, Baoding 071000, China; \\ a76232696@qq.com
}

Keywords: Mini-electrical vehicle; Frame; Modal analysis; Optimize.

\begin{abstract}
Geometry model and finite element model of the mini-electrical vehicle frame are constructed by catia and hypermesh. Then, the natural frequency of the lower mode and vibration mode which belong to the electrical vehicle are calculated by radioss. At last, comparing with the excitation frequency of the vehicle, the vibration character is analysed, and then the flaw is optimized though the size optimization.At here,we choose the thick of beam to be design variables. After checking the optimal result of the frame, the optimal frame can fulfill the static force requirements of the vehicle. So,the optimization can elevate the natural frequency of the frame, and the frame will perform better vibration character.
\end{abstract}

\section{Introduction}

The mini-electrical vehicle frame as the major component of the vehicle which carry motor, battery and some other force can influence safety and comfortableness ${ }^{[1]}$. The vehicle will be produced intense vibration because of the change of velocity and direction and the road irregularities. If the exciting frequency is close to the natural frequency of the vehicle, it will occur resonance and produce severe vibration and noise ${ }^{[2]}$. So this thesis analyses the natural frequency of the vehicle frame and optimizes the structure of the electrical vehicle frame by the means of size optimization.

\section{Theory of Modal Analysis.}

Modal that can be used for studying the dynamic performance of structure is the character of vibration. Every structure has its own modal, and each modal parameter is composed of modal frequency, modal damping and modal shapes ${ }^{[3]}$. The vehicle frame is a system of multi-degree freedom ${ }^{[4]}$. Whatever the damping changes, the mode vibration can be composed of addition method of the modal frequency, damping ration, and natural modes ${ }^{[5]}$. Therefore, the motion differential equation can be expressed by the following ${ }^{[6]}$ :

$$
[\mathrm{M}]\{\ddot{\mu}\}+[\mathrm{C}]\{\dot{\mu}\}+[\mathrm{K}]\{\mu\}=0 .
$$

Where:[M]-mass matrix; [C]-damping matrix; [K]-stiffness matrix.

$\{\mu\}$-displacement vector; $\{\stackrel{\mu}{\mu}\}$-elocity vector; $\{\stackrel{\mu}{\mu}\}$-acceleration vector.

By analysing the modal, we can ignore the damping because it has no effect on the natural frequency of the frame. So we can turn the formula 1 into formula 2:

$$
\left([\mathrm{K}]+\omega^{2}[\mathrm{M}]\right)\{\mu\}=0 .
$$

Where: $\omega^{2}$-eigenvalue which is the square of the natural frequency.

After solving the characteristic equation which is a vibration system with no damping, we can obtain the natural frequency " $\mathrm{w}_{\mathrm{i}}$ ” $(\mathrm{i}=1,2 \ldots, \mathrm{n})$.

Finite Element Modal and Geometry Modal of the Frame. 
The frame is composed of some carlings as the fig 1 shows. We import the geometry modal into the hypermesh, and choose the pshell element to divide the grid of the modal ${ }^{[7]}$. This thesis chooses the dimension of the grid element that is $10 \mathrm{~mm}$ because of the overall dimension of the frame and the density of the element. Then the Spot element is chosen to simulate the welding spot of the frame. At last, the FEM has been created as fig 2.

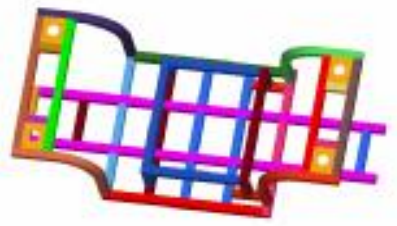

Fig. 1 geometry model of the frame.

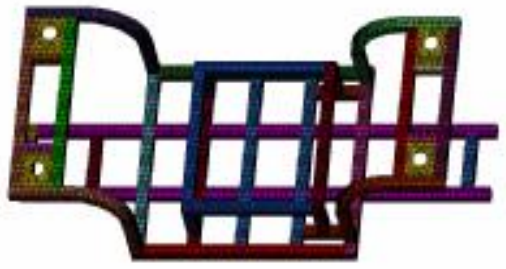

Fig.2 finite element model of the frame.

\section{Modal Analysis of the Frame.}

Result of the Constrained Modal for the Frame. Vibration of any structure can be expressed by the linear combination of each natural mode of vibration. The lower mode of vibration has more effect than higher mode of vibration ${ }^{[8]}$. Therefore, the major dynamic performance is decided by the lower mode of vibration. According to the fig 3-12, this thesis calculates the natural frequency and the mode of vibration of the first 10 order which have eliminated the rigidness modal.

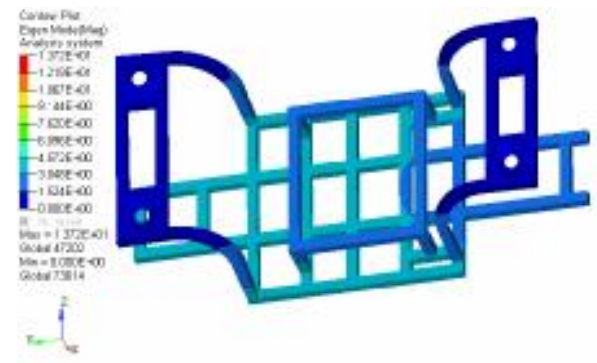

Fig.3 the first modal of the frame.

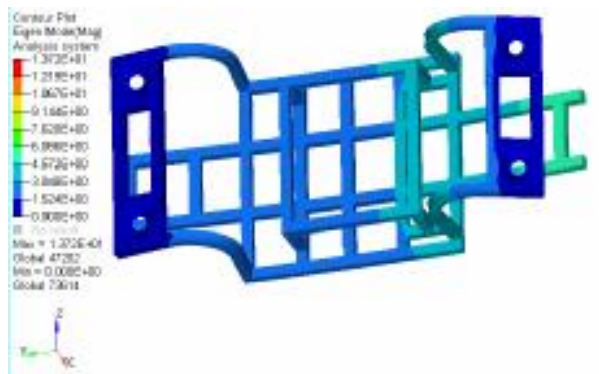

Fig. 5 the third modal of the frame.

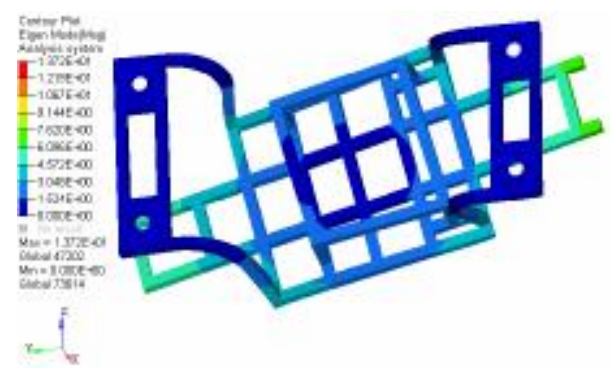

Fig.7 the fifth modal of the frame.

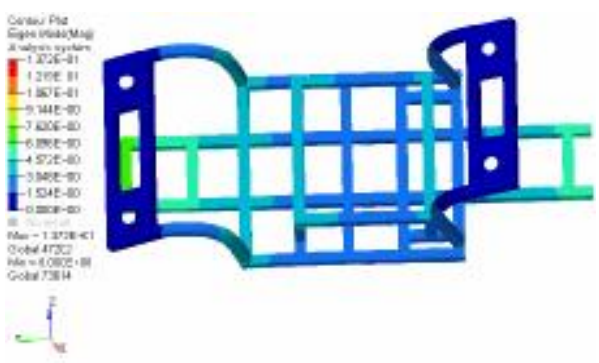

Fig.4 the second modal of the frame.

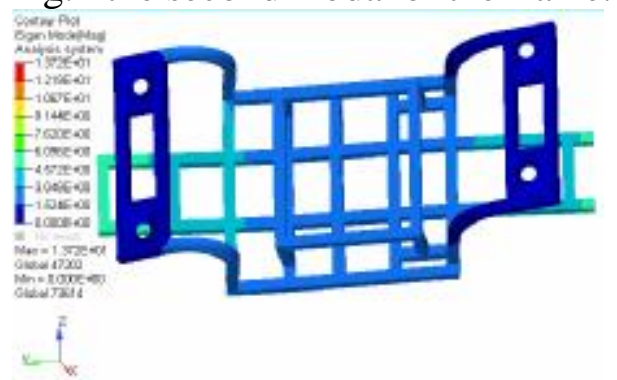

Fig.6 the fourth modal of the

frame

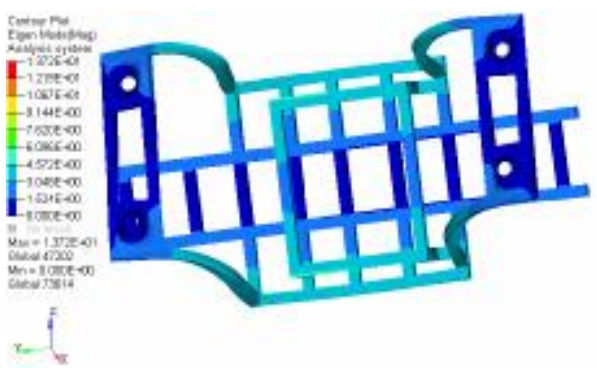

Fig. 8 the sixth modal of the frame. 


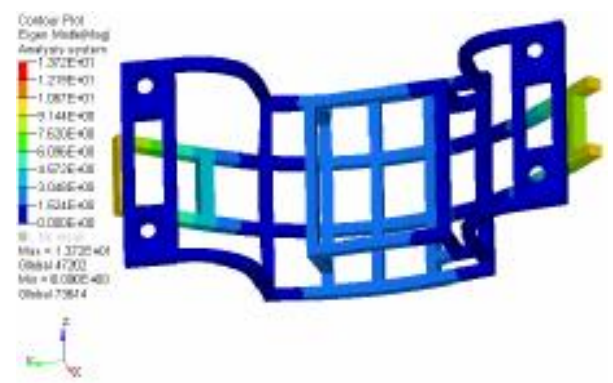

Fig.9 the seventh modal of the frame.

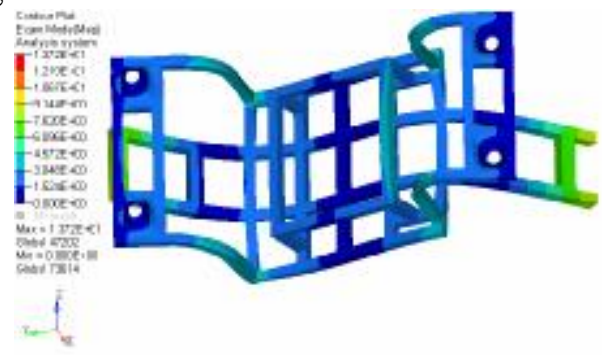

Fig. 11 the ninth modal of the frame.

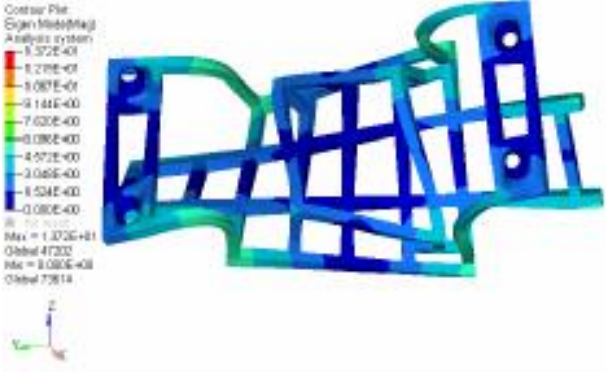

Fig.10 the eighth modal of the frame.

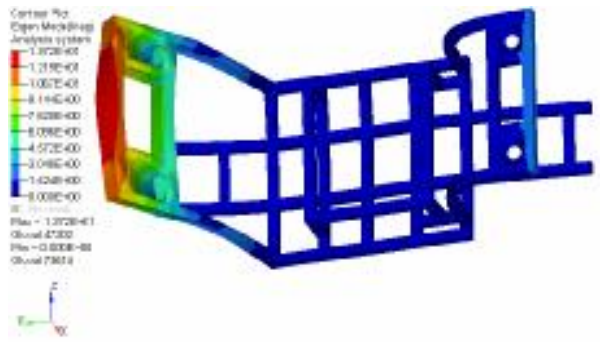

Fig.12 the tenth modal of the frame.

\begin{tabular}{cc}
\hline Order & Frequency[Hz] \\
\hline 1 & 17.19 \\
2 & 25.97 \\
3 & 29.16 \\
4 & 35.53 \\
5 & 35.63 \\
6 & 57.56 \\
7 & 72.64 \\
8 & 104.53 \\
9 & 112.96 \\
10 & 137.03 \\
\hline
\end{tabular}

The Result of the Modal Analysis. It is obvious that the performance of one car is decided by the dynamic performance of the bend and torsion. According to the fig 3-12, the first mode of vibration shows it bending towards left, and the deformation is not so serious. The second is composed of bend and torsion which directs lengthways, and the back of the frame suffers serious deformation. The third shows the front and back of bend, the most serious deformation occurs at the position of the back suspension. The fourth also displays bend modal and the back of the frame subjects to big deformation. From the fifth mode of vibration, we can see the sides of the frame subjected to serious torsion deformation. The affect together of the bend and torsion occurs in the sixth. From the seventh to the last, we can see the ultimate deformation of the frame.

\section{Size Optimization of the Modal for the Frame}

Excitation Source Analysis of the Electrical Vehicle. For the electrical vehicle, there are two types of excitation source. One comes from road irregularity, and the other comes from the vibration of motor. When the electrical vehicle works on the road, we know that the vibration frequency which is caused by road irregularity is below $10 \mathrm{~Hz}$ and the rotate speed of the motor which range from $1500 \mathrm{r} / \mathrm{min}$ to $5000 \mathrm{r} / \mathrm{min}$ can produce vibration frequency that is between $2.5 \mathrm{~Hz}$ to $20 \mathrm{~Hz}$. From the modal calculation, we find that the first order natural frequency may occur resonance. So we should do some size optimization in order to increase the first order natural. frequency. 


\section{Optimal Design of the Dimension of the Frame.}

Optimal Dimension. In size optimization, the thickness of a structure or the mass is often used for achieving the optimization. Therefore, some thickness of the beam which belongs to the frame is used for optimizing the first natural frequency. When in the optistruct which belongs to a module of hyperwork, objective function, design variable and constraint condition are all needed to created. So, in order to avoid resonance, the first order frequency is defined objective function; the two carlings in the middle and the two separated beams in the front and back and the five beams in the middle of the frame are considered as design variable, at the same time, the mass of the FEM is constrained between 0.1T to $0.2 \mathrm{~T}$.

The Result of the Optimization. As the fig 13 and tab 2 shows, the result of the optimization is obtained.

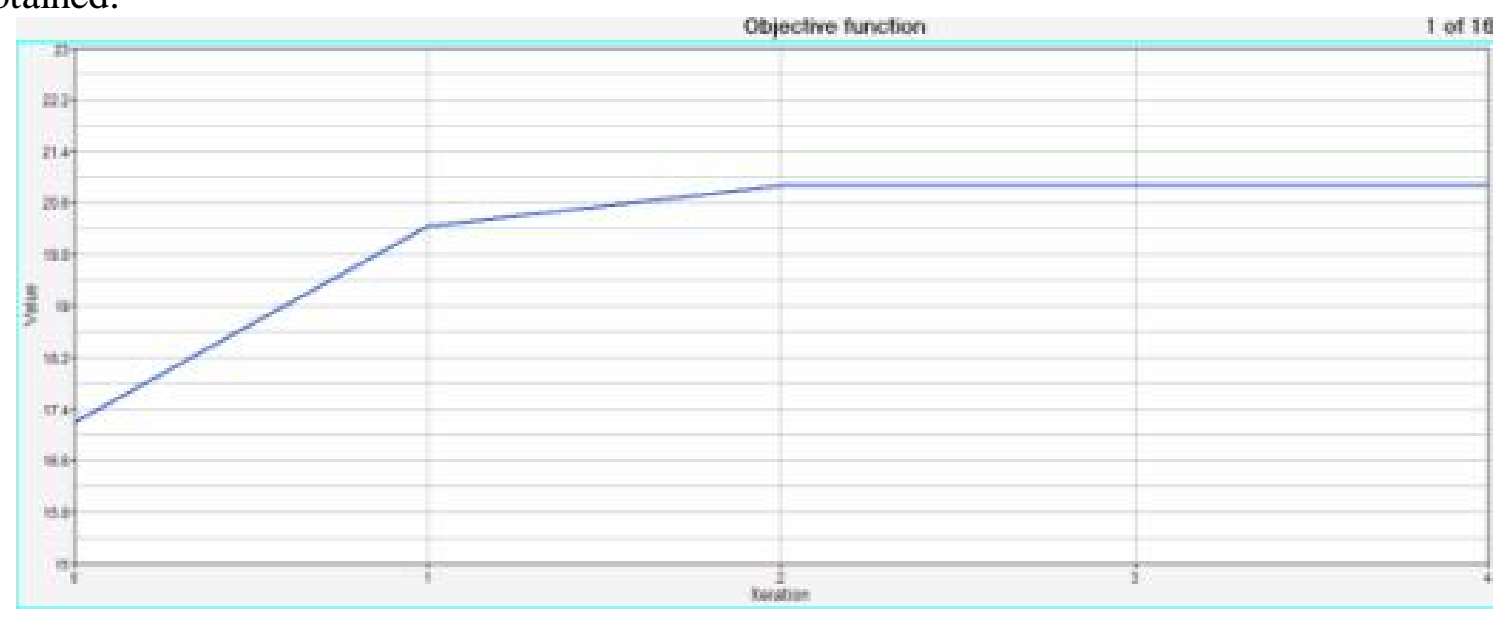

Fig.13 the iteration curve of objective.

Table 2 The result of the optimization.

\begin{tabular}{|c|c|c|c|c|c|}
\hline $\begin{array}{l}\text { Optimize } \\
\text { parameter }\end{array}$ & Number & Initial & Minimum & Maximum & $\begin{array}{c}\text { Optimal } \\
\text { result }\end{array}$ \\
\hline $\begin{array}{c}\text { Objective } \\
\text { function[ } \\
\mathrm{Hz}]\end{array}$ & Frequency & 17.19 & & & 20.09 \\
\hline $\begin{array}{c}\text { Constrait } \\
\text { condition[ } \\
\mathrm{T}]\end{array}$ & Mass & 0.137 & 0.1 & 0.2 & 0.12 \\
\hline \multirow{9}{*}{$\begin{array}{c}\text { Designvari } \\
\text { able }[\mathrm{mm}]\end{array}$} & Left carling & 3 & 1 & 5 & 2 \\
\hline & Right carling & 3 & 1 & 5 & 2 \\
\hline & Front beam & 2 & 1 & 5 & 1 \\
\hline & Back beam & 2 & 1 & 5 & 1 \\
\hline & $\begin{array}{l}\text { The first } \\
\text { middle beam }\end{array}$ & 3 & 1 & 5 & 3 \\
\hline & $\begin{array}{l}\text { The second } \\
\text { middle beam }\end{array}$ & 3 & 1 & 5 & 1.5 \\
\hline & $\begin{array}{l}\text { The third } \\
\text { middle beam }\end{array}$ & 3 & 1 & 5 & 1.5 \\
\hline & $\begin{array}{l}\text { The fourth } \\
\text { middle beam }\end{array}$ & 3 & 1 & 5 & 1.5 \\
\hline & $\begin{array}{l}\text { The fifth } \\
\text { middle beam }\end{array}$ & 3 & 1 & 5 & 2.5 \\
\hline
\end{tabular}




\section{Verification Result of Optimization for the Frame.}

After optimization, we must know whether the optimal result can fulfill the stress and deformation of the vehicle. When full-loaded electrical car works on the better road with constant velocity, the frame will subject to some constraints and vertical load.

Boundary and Load. The load of the frame major comes from the weight of the passengers, battery and motor. So we load uniform load $0.08 \mathrm{Mpa}$ on the fifth and sixth beam to simulate the battery' s weight, and load $750 \mathrm{~N}$ in the middle of the battery beam to simulate the weight of the passengers, and load $600 \mathrm{~N}$ in the middle of last beam to simulate the weight of the motor. Then the suspension of the frame needed to be constrained. The assembly place of the left front suspension should be constrained the degree of freedom which include UX,UY,UZ. The assembly place of the right front suspension should be constrained the degree of freedom which include UX,UZ. The assembly place of the left back suspension should be constrained the degree of freedom which include UY,UZ. The assembly place of the right back suspension should be constrained the degree of freedom which include UZ. Then release all of the rest degree of freedom.

The Result of Statics Analysis. After loading constrain and force, the stress and deformation has been calculated through optistruct which is a solver of hyperwork, as the fig 14-15 shows:

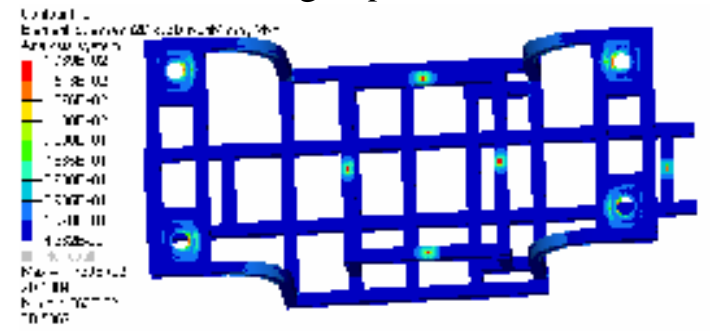

Fig.14 the stress distribution of the optimal frame

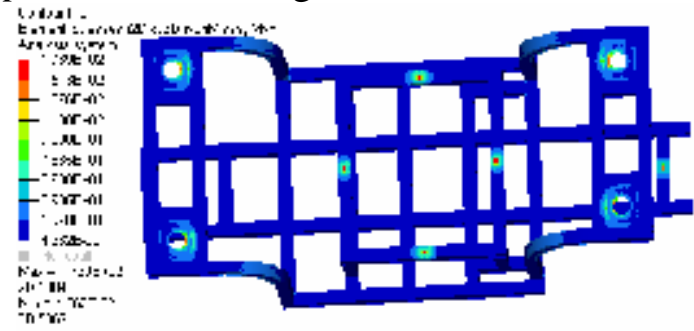

Fig.15 the deformation of the optimal

frame

The fig shows that most of the stress distribute at the position of the suspension, the max stress is $176.9 \mathrm{Mpa}$, and the position of the battery beam has the biggest deformation, but the max deformation is $1.071 \mathrm{~mm}$, which is much smaller than $10 \mathrm{~mm}$. The material of the electrical vehicle is Q235, so the optimal frame can fulfill the stress and deformation.

\section{Conclusions.}

At first, this thesis analyses the modal of a mini-electrical vehicle, and obtains the natural frequency and the mode of vibration of the first ten order. Then, the resonance of the frame is discussed. At last, the size optimization of the first natural frequency is analysed and the first natural frequency can increase through changing the thickness of the beams. Therefore the frame can avoid occurring resonance with the motor.

\section{References}

[1] Chen Zhi-yong, Shi Wen-ku, Shen Zhi-hong: Vibration and Shock, Vol.29(10):244-246.(2010)

[2] Chen Wei, Li Jun: Develop and Research, Vol.7:18-20. (2011)..

[3] Guo Chang-cheng: Modal Analysis and Structure Optimization of Car Frame, (MS., Jilin university, China,2011), p.26.

[4] Ye Mian: Finite Element Analysis and Optimization of LightTruck.Wuhan, (MS.,Wuhan University of Technology. China, 2007). p.22

[5] Zhang Yi-min: Vibration Theory. (Beijing: Tsinghua University Press. China 2006). p.5

[6] Jin Xiao: Vehicle Vibration. (Shanghai Tongji University Press. China 2003). p.57 
[7] Wang Meng: Research of Lightweight of Automobile. (MS., Shangdong University of Technology. China,2011). p.15.

[8] Zong Wang-bing, Wang Jian: Vibration and Shock, Vol.20(5):134-135.(2009). 